\title{
Comparing the Results of Treatment Methods of Casting and Bandage of Ankle Sprain in the Patients Who Referred to the Emergency Department of Poursina Hospital in the First Half of Year 2019
}

\author{
Khashayar Cyrus \\ Guilan University of Medical Sciences \\ Masoud Fallah Khoshghalb \\ Guilan University of Medical Sciences \\ Kamran Asadi ( $D$ Kasadi67@yahoo.com ) \\ Guilan University of Medical Sciences
}

\section{Research}

Keywords: Ankle sprain, Recurrent sprain, Activity restriction, Short cast of leg, Ankle bandage

Posted Date: January 19th, 2021

DOI: https://doi.org/10.21203/rs.3.rs-147910/v1

License: (c) (i) This work is licensed under a Creative Commons Attribution 4.0 International License.

Read Full License 


\section{Abstract}

Background: The purpose of this study is a comparative survey of the effect of casting and bandage treatments in ankle sprain in order to be effective in determining the more desirable method for returning the patients to work and activities as fast as possible especially in important sport activities.

Methods: In this study the referents to Emergency Department of Poursina hospital whose diagnosis was ankle sprain and needed treatment have been used. The patients who have been examined, categorised based on Clanton and Mcgravey classification and the intensity of ligaments injury in type II, group II, type A. (type II: unstable ankle with positive anterior drawer test or positive talar tilt test or both, group II: athlete or high demand patient, type A: negative radiographic stress test; functional treatment). The patients who had necessary criteria to enter this study have been divided into two groups A (casting) and B (bandage) randomly. Then, they have been re-examined after 3, 6 and 12 weeks of treatment and their cast or bandage has been removed and re-examined and the results of treatment have been assessed and compared in terms of total treatment or recurrent sprain and returning to work and activities and pain intensity.

Results: Pain intensity based on VAS had lower average in cast group comparing to bandage group after 3 and 6 weeks and this difference was statistically significant. AHS criterion in both groups had the same average after 3,6 and 12 weeks. Activity restriction time was lower in cast group comparing to bandage group significantly.

Conclusions: This study showed that cast therapy led to reduction of activity restriction time and consequently fast returning to work and daily activities, but in bandage group pain intensity reduced faster.

\section{Background}

Muscular-skeletal injury inflicts massive disability to people and health care systems. Especially, ankle is the most common anatomical part of body that would be hurt in people with high athletic or military activities $[1,2]$. Due to high prevalence, high treatment expenses and work absence time, ankle injury is one of the notable and important problems in medicine and requires preventive strategies and pedagogical priorities and resources to reduce that event.

The study conducted by Nabian et al. (2017) on referents to Shariati hospital in Tehran revealed that about $53.5 \%$ of joint injuries related to ankle injuries and was more common in the youth and had different distribution pattern based on age and gender [3].

In the USA almost 23000 ankle sprain occurred a day [4]. The study of Garrick and Requa (1998) mentioned that $25 \%$ of leg injury related to ankle and $85 \%$ of it related to ankle sprain. This study had been conducted on athletes referred to sports-medicine centre of California/ America in a 6.5 year period [5]. Also, it was revealed that ankle sprain background was a predisposing factor [6]. 
Ankle sprain is more prevalent in football, volleyball and other sports which need quick movement and plenty change of directions [4]. There are some factors which are effective in ankle sprain. Internal factors consist of joint instability, Shortness of muscles, non-symmetry of muscles strength, previous injuries, insufficient rehabilitation, mental stresses and the way of walking. External factors are as follows: sport skills level, competition and practice level, rules and faults of games [7]. Usual signs are swollen and painful ankle that is mostly below internal or external malleolus and depend on the injury type, ankle movements especially painful rotational movements. In case of total ligament rupture, ankle rotation due to talus bone subluxation and re-reduction, rattles and is tangible when touching $[8,9]$.

Treatment proceedings are different based on injury severity and symptoms and consist of supportive treatments such as care recommendations, symptom therapy and joint immobilization by use of cast or bandage and rebuilding restorative surgery. It is notable that negligence in correct treatment causes repetition of injury and consequently joint instability $[10,11]$.

Since the most common treatment for this complication is joint immobilization by using short cast from the base of toe to tibia protrusion and bandage from the middle point of leg to ankle, we decided to study these two kinds of treatment more precisely and comparatively $[12,13]$. So, the effect of bandage and casting on pain intensity, joint activity restriction time, and Ankle Hindfoot Scale (AHS) was studied and compared. Also, based on previous studies and the effect of age, gender, body mass index (BMI), and recurrent sprain on ankle health $[14,15]$, we decided to study and compare these specificities on pain criteria, activity restriction and AHS in two groups.

\section{Methods}

\section{Ethical consideration}

This study has been done in the first half of year 2019 on the patients who suffered ankle sprain and referred to Emergency Department of Poursina hospital in Rasht, Gilan, Iran. This project has been approved and coordinated by research council of Gilan University and research moral committee and performed in Emergency Department of Poursina hospital. This survey has been performed based on health criteria. Also, the patients decided to participate in this study by knowing possible cons and pros of

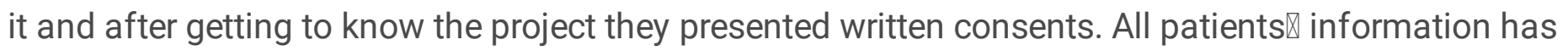
been recorded as their secrets in questionnaires and it was accessible just for the executives.

In this project the participants were free to enter or exit whenever they wanted. Also, it was mentioned in the written consent that probable losses and damages due to taking part in the study would have been compensated. Accordingly, if proven that the loss was due to the project, the executives were responsible to compensate all financial losses and damages. All personal information (name, age, gender, specific diseases background, weight, height, address and phone number) was gathered from the patients.

\section{The population under study and individual profile}


The patients with ankle sprain diagnosis have been examined and categorized into two groups based on

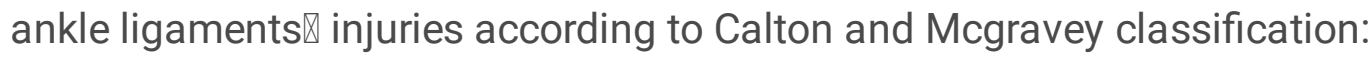

Type 1: stable ankle to clinical testing with anesthesia if necessary symptomatic treatment

Type 2: unstable ankle with positive anterior drawer test or positive talar tilt test or both and will be divided into two following groups:

Group I: non-athletes or older patient, functional treatment.

Group II: athlete or high-demand patient whom will be categorized into three types.

Type A: negative radiographic stress test, functional treatment.

Type B: positive tibiotalar radiographic stress test surgical repair.

Type C: subtalar instability, functional treatment $[12,13]$.

Since the treatment for types 1 and 2 is different, type 1 exited the project and just the patients of type 2 , group II and type A were studied and divided into two groups randomly:

1- Treatment group 1 (39 people): bandage treatment

2- Treatment group 2 (39 people): short cast treatment

\section{The criteria of being exited the treatment in the project were:}

1- Neuropathic patients (diabetic or other causes)

2- Injured tissue varicose veins patients

3- Diabetes suffering

4- Ankle fraction background

5- Previous sprain or surgery background

6- The patients who needed surgery

7- Low demand and inactive patients

8- The patients with opposite limb weakness that caused pressure on the limb under study 
Then, pain features were studied in 3, 6 and 12 weeks after the treatment based on Visual analogue scale (VAS) $₫$ joint activity limitation and AHS.

\section{Definitions}

\section{Ankle sprain}

When the pressure on joint ligaments is more than their tolerance, sprain and twisting will occur. If the strike is mild it causes ligament stretching and mild rupture, but in case of severe strike, ligament rupture will be complete [16].

\section{Pain based on visual analogue scale}

It is Visual Analogue Scale from 0 to 10 and the patients will be explained that 0 means no pain and 10 means the maximum pain level and they will be asked to describe their pain level based on this range of numbers [17].

\section{Activity restriction time}

It means the time that the patient will return to his routine activities.

\section{Ankle hind foot scale}

It is one of the measurement scales for treatment results in the patients with ankle injury and includes some parts of patient and physician reports [18].

\section{Statistical analysis method}

Necessary amount of the specimen for comparing the results of cast and bandage treatments in ankle sprain patients by $95 \%$ reliability and $80 \%$ test strength and based on the study results [19] and according to pain intensity after the first two weeks and considering clinical difference of at least one criterion deviation of bandage pain score in 39 people of each group was determined.

$$
\begin{aligned}
& 1-\alpha=\% 95 \Rightarrow Z_{1-\frac{a}{2}}=Z_{\% 975}=1 / 96 \\
& 1-\beta=\% 80 \Rightarrow Z_{1-\beta}=Z_{\% 80}=0 / 84
\end{aligned}
$$

(standard deviation of bandage pain score) $s 1=1.2$

(standard deviation of plaster pain score) s2 $=2.4$

$d=$ expected significantly $=1$ SD bandage 
$n=\frac{\left(z_{1-\frac{q}{2}}+z_{1-\beta}\right)^{2}\left(S_{1}^{2}+S_{2}^{z}\right)^{2}}{d^{2}}=\frac{(1.96+0.84)^{2} \times\left(2.4^{2}+1.2^{2}\right)^{2}}{1.2^{2}}$

\section{$n=39$ Pergroup}

The data was analysed statistically based on SPSS software and version 20. Data dispersion distribution was considered as normal data by use of Shapiro-Wilk Test and $95 \%$ reliability $(P<0.05)$. Chi square test has been done to compare redundancy of members in two under study groups.

To compare the amount of dependent variables averages (pain and AHS), in two under treatment groups repeated measure ANOVA test was conducted and personal features (age, gender, BMI, sprain recurrence) were considered as covariates. Also, multivariate analysis of covariance test was used. The average amount of dependent variables \pm criterion deviation is mentioned in the text. Tests significance level was determined by $\mathrm{P}<0.05$.

\section{Results}

Table 1 shows redundancy distribution in two cast and bandage groups in case of age, gender, $\mathrm{BMI}$ and recurrent sprain. Patients redundancy distribution didn't show any significant statistical difference based on personal characteristics $(P<0.05)$. (Table 1$)$. According to RM-ANOVA test, pain intensity in two cast and bandage groups showed reduction significantly $(P<0.001)$. Totally based on chart 1 , pain intensity on VAS scale in bandage group indicated lower average and pain reduction in this group was faster than cast group, although the average scale reached zero after 12 weeks in both groups. 
Table 1

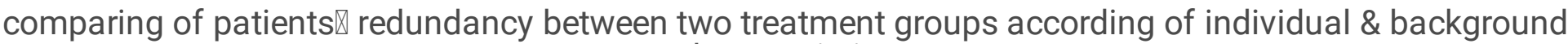
characteristics

\begin{tabular}{|c|c|c|c|c|c|c|}
\hline \multirow[t]{3}{*}{ Individual profile } & & \multicolumn{4}{|c|}{ Method of treatment } & \multirow{3}{*}{$\begin{array}{l}\text { P-value } \\
* 234.0\end{array}$} \\
\hline & & \multicolumn{2}{|l|}{ Bandage } & \multicolumn{2}{|l|}{ cast } & \\
\hline & & Number & Percentage & Number & Percentage & \\
\hline \multirow[t]{4}{*}{ Age } & $20<$ & 6 & 50.00 & 6 & 50.00 & \\
\hline & 20 to 29 & 12 & 44.44 & 15 & 55.56 & \\
\hline & 30 to 39 & 10 & 41.67 & 14 & 58.33 & \\
\hline & $40<$ & 11 & 73.33 & 4 & 26.67 & \\
\hline \multirow[t]{2}{*}{ Gender } & Male & 17 & 41.46 & 24 & 58.54 & \multirow[t]{2}{*}{ *112.0 } \\
\hline & Female & 22 & 59.46 & 15 & 40.54 & \\
\hline \multirow[t]{4}{*}{ BMI } & Underweight & 2 & 33.33 & 4 & 66.67 & \multirow[t]{4}{*}{$\star \star 916.0$} \\
\hline & Normal & 18 & $51 / 43$ & 17 & 48.57 & \\
\hline & Overweight & 17 & 51.52 & 16 & 48.48 & \\
\hline & Obesity & 2 & 50.00 & 2 & 50.00 & \\
\hline \multirow[t]{2}{*}{ Recurrent sprain } & Positive & 3 & 75.00 & 1 & 25.00 & \multirow[t]{2}{*}{$\star \star 615.0$} \\
\hline & Negative & 36 & 48.65 & 38 & 51.35 & \\
\hline \multicolumn{7}{|c|}{$\begin{array}{l}\text { Underweight: BMI } \leq 18.5 \text {, Normal BMI: } 18.5<\text { BMI } \leq 24.9 \text {, Overweight: } 25 \leq \text { BMI } \leq 29.9 \text {, Obesity I: } 30 \\
\leq \mathrm{BMI} \leq 34.9\end{array}$} \\
\hline \multicolumn{7}{|l|}{ * K2 test } \\
\hline ** Fisher test & & & & & & \\
\hline
\end{tabular}

Also, pain intensity didn't show significant difference at first (admission time), $(P=0.760)$ but after 3 and 6 weeks of treatment we faced significant lower average in bandage group than cast group $(P<0.001)$, but after 12 weeks of treatment it didn't have significant difference $(P=0.999)$ (Fig. 1).

According to RM-ANOVA test, score changes of AHS have been measured from 3 to 12 weeks in cast and bandage groups and a significant uptrend was seen, but the group didn't have any significant effect on AHS scale $(P<0.32)$. As a whole, time factor didn't have any significant effect on AHS scale $(P=0.610)$ and the effect was the same for interaction factor $(P=0.072)$. It means that recovery trend in two kinds of treatments (cast and bandage) was the same and didn't have significant difference statistically (Table 2). 
Table 2

bandage \& cast treatment effects on AHS average \& deviation criterion after $3,6,12$ weeks of treatment.

\begin{tabular}{|llllll|}
\hline variable & \multicolumn{2}{l}{ Treatment group } & \multicolumn{3}{l|}{ P-values** } \\
\hline AHS* & Bandage & cast & Group & Time & Group $\times$ Time \\
\cline { 2 - 6 } & $76.5 \pm 3.6$ & $76.01 \pm 6.83$ & $0 / 32$ & 0.61 & 0.072 \\
\hline \multirow{2}{*}{ *Ankel-Hintfood Scale } & & & \\
\hline \multirow{2}{*}{ **significant value $\mathrm{P}<0.05$} & & & \\
\hline
\end{tabular}

Activity restriction time in cast group had less average than bandage group and this difference was statistically significant $(P=0.002)$ (Table 3 ). Age, gender and $B M I$ are covariates and have significant effects on joint activity restriction time $(P=0.002)$ and joint activity restriction time in women at the age range of 20-29 with normal BMI in both treatment groups showed significant differences (Fig. 2).

Table 3

comparing of activity restriction time in bandage \& cast groups

\begin{tabular}{|llll|}
\hline variable & treatment & & \\
\hline Activity restriction time & Bandage & cast & P-Value \\
\cline { 2 - 4 } & $32.3 \pm 14.1$ & $29.6 \pm 11.7$ & $0.002^{*}$ \\
\hline * significant value $\mathrm{P}<0.05$ & & \\
\hline
\end{tabular}

\section{Discussion}

The purpose of this study is an exact and comparative investigation about the effect of two kinds of treatments i.e.; bandage and casting in patients suffering from ankle sprain, on pain scale based on VAS scale, joint movement restriction and AHS. Also, due to previous studies about the effects of age, gender and $\mathrm{BMI}$ on ankle injury prevalence, we decided to study and compare those factors (pain scale, joint movement restriction and AHS) on both groups based on age, gender and BMI.

This study showed that most patients were in the age range of 20-30 and their average age and deviation factor was $30.4 \pm 9.7$ and most of them were male. Abundance distribution of age group, gender and BMI and recurrent sprain in both groups didn't show significant statistical differences. In various studies, patients $\llbracket$ average age was almost the same. In Verhagen et al. (2000) study, the average age in bandage group was $36.03 \pm 15.5$ [20] and in cast group was $37.5 \pm 13.9$ [5]. In Kannus and Renstromb (1991) study the age group of 18-35 suffered ankle sprain more than others [4].

In Garrick and Requa (1989) study cured injuries were studied in a clinic in a 6.5 year period of time and it became clear that $25 \%$ of leg injuries related to ankle and sprain was $85 \%$ of ankle injuries. The survey 
indicated that most patients who suffered sprain were in the age range of 25-35 and it could have been due to more sport activities in this range than others [5].

The percentage of recurrent sprain in bandage group was $7.7 \%$ and in cast group was $2.6 \%$, but no significant difference was seen in two treatment groups statistically. In Saltzman et al. (2005) study the amount of recurrent sprain was lower in cast group than bandage one [21]. In Peer et al. (2009) survey no significant difference was seen in two treatment groups statistically in case of recurrent sprain in one month after treatment beginning, but there was a significant difference after three months treatment and ankle recurrent sprain in all time periods was more in bandage group than cast one [22]. Although there was a report in previous studies about significant difference between ankle recurrent sprain in bandage and cast groups, it could be because of small population of statistical society and it might become significant with more patients and more follow ups.

Pain scale based on VAS at the first time was the same and without significant difference statistically but in different times of measurement it showed downtrend in both groups. Totally pain in bandage group had lower average than cast group and downtrend slope was more in bandage group, but after 3 and 6 weeks, pain scale was less than cast group significantly. Finally, after 12 weeks pain didn't have significant difference between two groups and pain in both of them reached zero. These results are along with other studies. In Almeida et al. (1999) survey pain scale was studied based on VAS scale and two weeks, one month and three months after treatment beginning in the patients who referred to emergency department and in all these time periods, pain intensity average was lower in bandage group than cast group [23]. Also, in Saltzman et al. (2005) study, bruise, inability to walk, pain and swelling were the most common complaints of patients and pain intensity was lower in bandage group than cast one [21].

In Rastegar et al. (2017) study 80 patients suffering from ankle sprain who referred to Alzahra hospital in Isfahan were studied and were put in two treatment groups (bandage group and immobilization one (cast)) without considering pain scale and just randomly. After 2 weeks, pain in bandage group showed significant reduction [19].

Probably, one reason of more pain score average in cast group was stiffness which is due to casting and this problem is less in bandage group. Activity restriction time in cast group had lower average than bandage group and the time was 29.6 and 32.3 respectively and this difference was significant. Also, age, gender and BMI as covariates had significant effects on joint activity restriction time. In the age range of 20-29 in females with normal BMI and just overweight there was a significant difference between two groups, such a way that activity restriction time in bandage group was more than cast group. It is possible that more activity and weight caused more pressure on injured ankle and lead to prolongation of recovery process and these findings need more studies.

In other surveys, activity restriction time was less in cast group. In Verhagen et al. (2000) study, activity restriction average time in bandage and cast groups was 25.66 and 18.98 respectively. It means that activity restriction time in cast group was so shorter than bandage one and it could have been due to shorter treatment period in cast group [20]. 
In Kannus and Renstrom (1991) study, the average time of recovery in patients with bandage and cast treatment was 47.93 and 37.5 days respectively and it can be concluded that recovery time in cast group was less than bandage group [4]. In Garrick and Requa (1989) study, the average time of recovery in patients with bandage treatment was 41.4 days and in cast group was 38.3 [24].

\section{Conclusion}

In this study, cast therapy led to reduction of activity restriction time and faster returning to work and daily activities and in bandage therapy we observed faster pain reduction, but there was not any significant difference in joint recovery score. According to the results of this study, it will be recommended that active and young people who need to go back to work and activities faster use cast therapy and low demand people and higher age range patients use bandage therapy because of thromboembolism side effect danger.

\section{Abbreviations}

AHS: Ankle Hindfoot Scale; BMI: body mass index; VAS: Visual analogue scale.

\section{Declarations}

\section{Acknowledgements}

Not applicable.

\section{Authors' contributions}

KS conducted online survey assembly, data extraction, and statistical analysis under the supervision of KA. KS, MFK and KA contributed to data interpretation, writing and revision of the manuscript. All authors read and approved the final manuscript.

\section{Funding}

Guilan University of Medical Sciences, Rasht, Iran

\section{Availability of data and materials}

The data that support the findings of this study are not publicly available. Data are however available from the authors upon reasonable request and with permission of Guilan University of Medical Sciences.

\section{Ethics approval and consent to participate}

This study was extracted from a research project at Guilan University of Medical Sciences (IR. GUMS. REC.1398.025). 


\section{Consent for publication}

Not Applicable

\section{Competing interests}

The authors declare that they have no competing interest.

\section{References}

1. Fong, D.T.-P., et al., A systematic review on ankle injury and ankle sprain in sports. Sports medicine, 2007. 37(1): p. 73-94.

2. Lievers, W.B. and P.F. Adamic, Incidence and severity of foot and ankle injuries in men's collegiate American football. Orthopaedic journal of sports medicine, 2015. 3(5): p. 2325967115581593.

3. Nabian, M.H., et al., Epidemiology of joint dislocations and ligamentous/tendinous injuries among 2,700 patients: five-year trend of a tertiary center in Iran. Archives of bone and joint surgery, 2017. 5(6): p. 426.

4. Kannus, P. and P. Renstrom, Treatment for acute tears of the lateral ligaments of the ankle. J Bone Joint Surg Am, 1991. 73(2): p. 305-312.

5. Garrick, J.G. and R.K. Requa, The epidemiology of foot and ankle injuries in sports. Clinics in sports medicine, 1988. 7(1): p. 29-36.

6. Theurillat, C., et al., Active ankle circumduction to identify mobility deficits in subacute ankle sprain patients. Journal of applied biomechanics, 2018. 34(1): p. 1-6.

7. Garrick, J.G., The frequency of injury, mechanism of injury, and epidemiology of ankle sprains. The American journal of sports medicine, 1977. 5(6): p. 241-242.

8. Chan, K.W., B.C. Ding, and K.J. Mroczek, Acute and chronic lateral ankle instability in the athlete. Bulletin of the NYU hospital for joint diseases, 2011. 69(1): p. 17.

9. Hubbard-Turner, T., et al., An acute lateral ankle sprain significantly decreases physical activity across the lifespan. Journal of sports science \& medicine, 2015. 14(3): p. 556.

10. Petersen, W., et al., Treatment of acute ankle ligament injuries: a systematic review. Archives of orthopaedic and trauma surgery, 2013. 133(8): p. 1129-1141.

11. Barg, A., et al., Subtalar instability: diagnosis and treatment. Foot \& ankle international, 2012. 33(2): p. 151-160.

12. Clanton, T.O., Athletic injuries to the soft tissues of the foot and ankle. Surgery of the Foot and Ankle, 1999: p. 1090-1209.

13. Clanton, T.O., et al., Qualitative and quantitative anatomic investigation of the lateral ankle ligaments for surgical reconstruction procedures. JBJS, 2014. 96(12): p. e98.

14. Gay, A., et al., Associations Between Body Mass Index and Foot Joint Pain in Middle-Aged and Older Women: A Longitudinal Population-Based Cohort Study. Arthritis care \& research, 2014. 66(12): p. 
1873-1879.

15. Hawke, F., K. Rome, and A.M. Evans, The relationship between foot posture, body mass, age and ankle, lower-limb and whole-body flexibility in healthy children aged 7 to 15 years. Journal of foot and ankle research, 2016. 9(1): p. 14.

16. Davda, K., et al., Peroneal tendon disorders. EFORT open reviews, 2017. 2(6): p. 281-292.

17. Stüber, J., et al., Normative data of the Visual Analogue Scale Foot and Ankle (VAS FA) for pathological conditions. Foot and ankle surgery, 2011. 17(3): p. 166-172.

18. Kitaoka, H.B., et al., Clinical rating systems for the ankle-hindfoot, midfoot, hallux, and lesser toes. Foot \& ankle international, 1994. 15(7): p. 349-353.

19. RASTEGAR, S., et al., COMPARISON OF THE RESULTS OF BANDAGING AND CASTING IN PATIENTS WITH FIRST-AND SECOND-DEGREE SPRAIN OF LATERAL ANKLE LIGAMENTS. 2017.

20. Verhagen, E.A., W. van Mechelen, and W. de Vente, The effect of preventive measures on the incidence of ankle sprains. Clinical Journal of Sport Medicine, 2000. 10(4): p. 291-296.

21. Saltzman, C.L., et al., Epidemiology of ankle arthritis: report of a consecutive series of 639 patients from a tertiary orthopaedic center. The lowa orthopaedic journal, 2005. 25: p. 44.

22. Peer, K.S., J.E. Barkley, and D.M. Knapp, The acute effects of local vibration therapy on ankle sprain and hamstring strain injuries. The Physician and sportsmedicine, 2009. 37(4): p. 31-38.

23. ALMEIDA, S., et al., Epidemiological patterns of musculoskeletal injuries and physical training. Medicine \& Science in Sports \& Exercise, 1999. 31(8): p. 1176-1182.

24. Garrick, J. and R. Requa, The epidemiology of foot and ankle injuries in sports. Clinics in podiatric medicine and surgery, 1989. 6(3): p. 629-637.

\section{Figures}




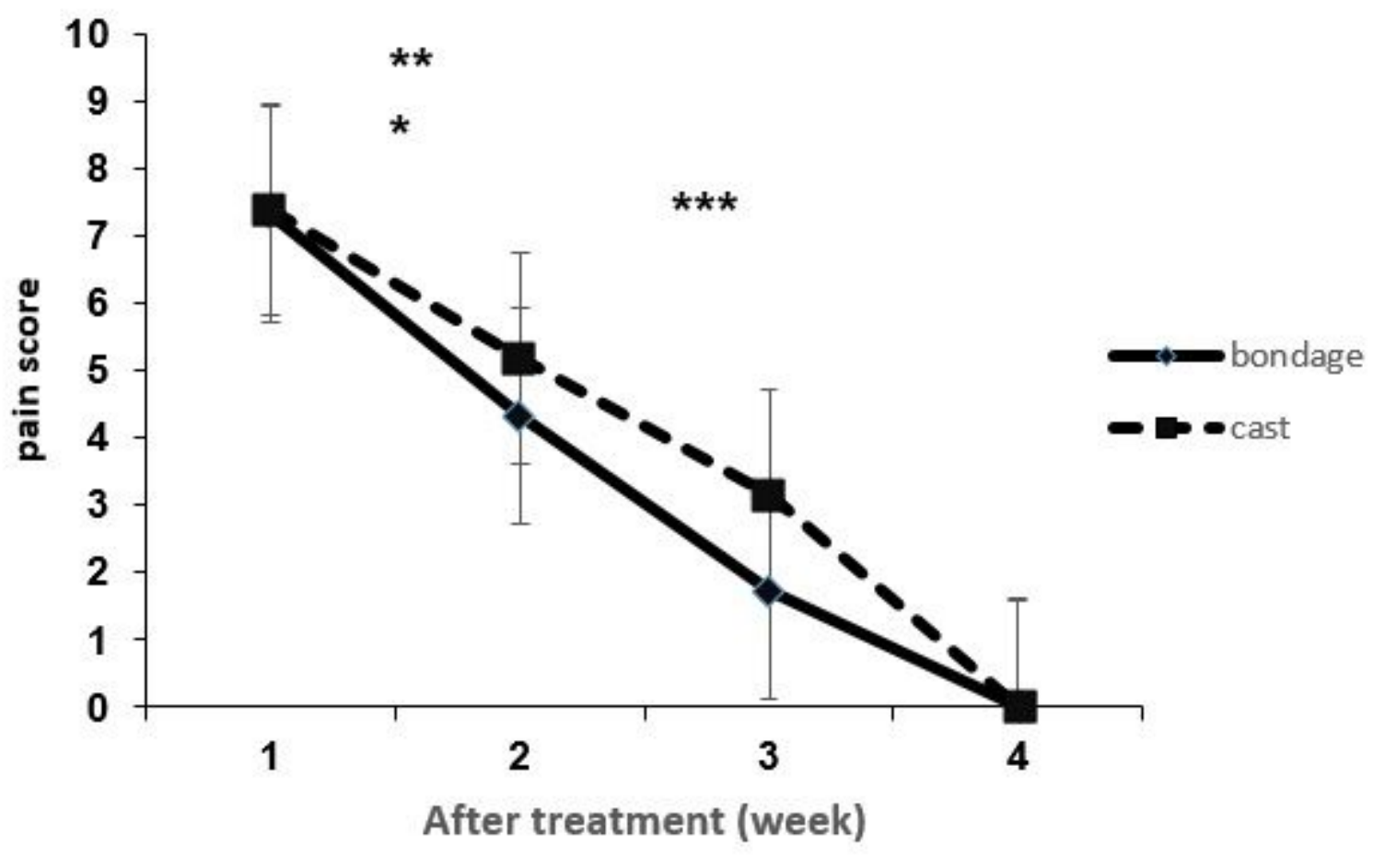

Figure 1

bandage \& cast treatment effects on pain score after $3,6,12$ weeks 

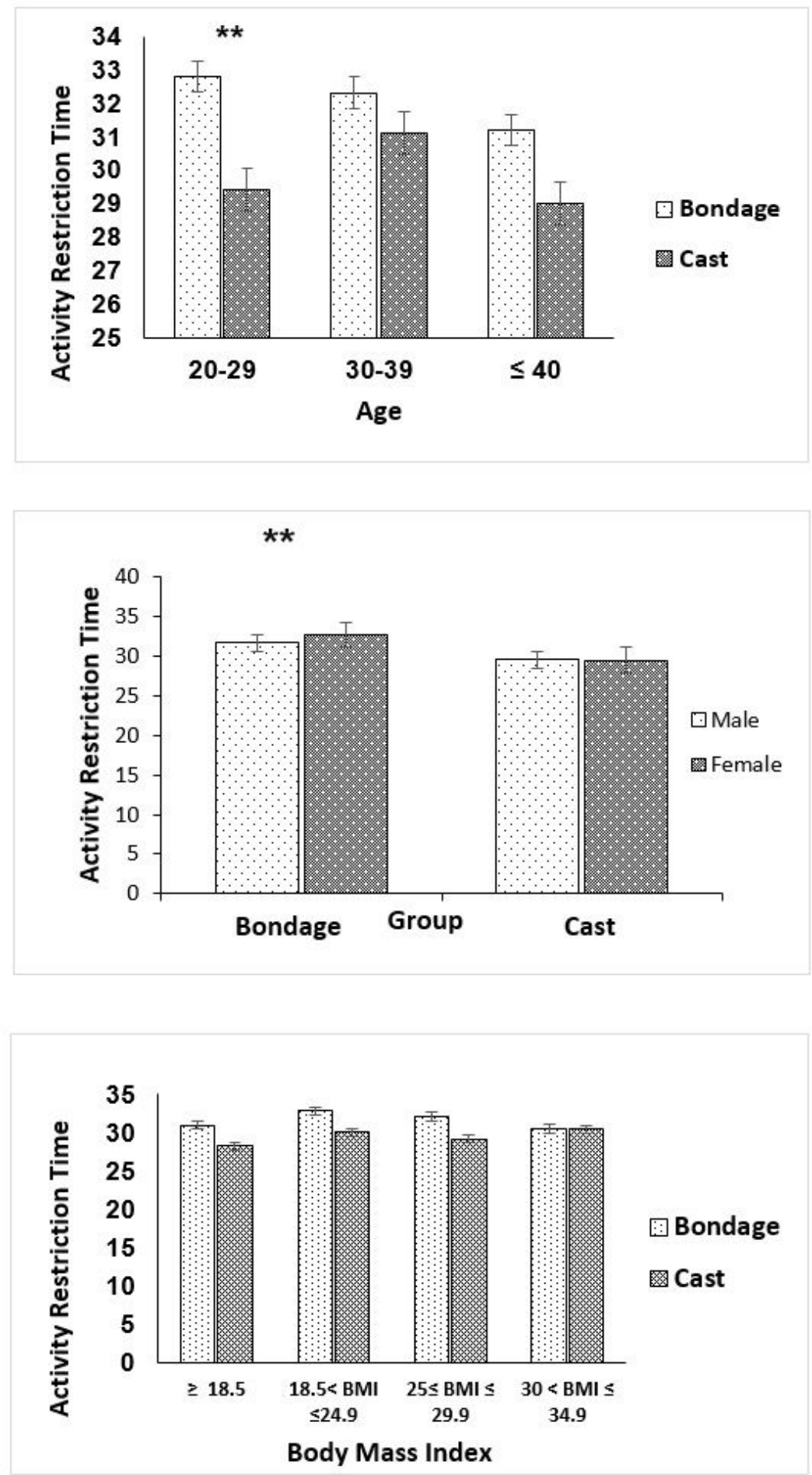

Figure 2

Age, Gender and BMI effect on activity restriction time in both treatment groups 